\title{
O CASO SEMENTYS: SEMEANDO O FUTURO
}

\author{
THE CASE OF SEMENTYS: SOWING THE FUTURE
}

\author{
ANDRESSA TERRA \\ Universidade de Santa Cruz do Sul - UNISC \\ Mestre pelo Programa de Pós-Graduação em Administração da UNISC \\ Orcid: 0000-0002-5983-6166 \\ E-mail: dessaterra@hotmail.com \\ Endereço: Av. Independência, 2293 - sala 205, Santa Cruz do Sul/RS \\ CRISTINA M. OSTERMANN \\ Universidade de Santa Cruz do Sul - UNISC \\ Mestre pelo Programa de Pós-Graduação em Administração da UNISC \\ Orcid: 0000-0001-8399-3519 \\ E-mail: cris.ostermann@gmail.com \\ ANA FLÁVIA HANTT \\ Universidade de Santa Cruz do Sul - UNISC \\ Mestre pelo Programa de Pós-Graduação em Administração da UNISC \\ Orcid: 0000-0003-4662-7151 \\ E-mail: ana.hantt@gmail.com

\section{JULIA SCHAEFER} \\ Universidade de Santa Cruz do Sul - UNISC \\ Mestre pelo Programa de Pós-Graduação em Administração da UNISC \\ Orcid: 0000-0002-2254-0724 \\ E-mail: julia.schaefer@pioneer.com
}

\section{RESUMO}

Trata-se de caso de estudo que apresenta questões relacionadas à internacionalização, especificando as etapas adotadas por uma empresa de sementes agrícolas para a entrada e consolidação no mercado externo. Para a discussão desse caso, utiliza-se o embasamento de conceitos oriundos das Teorias de Internacionalização, como a teoria de Uppsala, com foco no gradualismo e modos de entrada em novos países para discussão do caso da empresa Sementys, líder no segmento de sementes híbridas no seu país, Estados Unidos. A empresa entende que chegou o momento de ampliar a venda de seus produtos em outros mercados e, para isso, pretende valer-se da sólida reputação construída em sua trajetória. Em busca de novas oportunidades para a expansão, é que a companhia mapeia o Brasil, importante produtor agrícola. Nesse contexto, a empresa se deparou com o seguinte desafio: qual a estratégia a ser adotada para entrada no mercado de sementes no Brasil? Esse caso de estudo pode ser utilizado como instrumento de ensino em aulas dos cursos de Graduação e PósGraduação em Administração, Marketing e Comércio Internacional.

Palavras-chave: Caso de Estudo. Internacionalização. Agronegócio. 


\begin{abstract}
This case study presents issues related to internationalization, specifying the steps adopted by an agricultural seed company while entering and consolidating into a foreign market. To discuss this case, we use the basis of concepts from Internationalization Theories, such as Uppsala theory, focusing on gradualism and ways of entering new countries to discuss the case of Sementys, leader in the hybrid seed segment in its country, the United States. The company understands that the time has come to expand the sale of its products in other markets and, therefore, intends to count on the solid reputation built on its history. In search of new opportunities to expand, the company maps Brazil, an important agricultural producer. In this context, the company faced the following challenge: what is the strategy to be adopted to enter the seed market in Brazil? This case study can be used as a teaching tool in undergraduate and postgraduate courses in Business Administration, Marketing and International Trade.
\end{abstract}

Keywords: Teaching case. Internationalization. Agribusiness.

\title{
1 APRESENTAÇÃO
}

Os temas referentes à internacionalização têm ganhado destaque nos estudos em Administração nos últimos anos. Com a globalização e abertura de mercados, as estratégias de internacionalização de negócios têm ganhado foco. Marketing internacional ou internacionalização são temas ministrados nas instituições de ensino superior em nível de graduação e pós-graduação e essas disciplinas podem se apoiar em casos de ensino para melhor compreensão e aplicabilidade dos conteúdos ensinados.

Os casos de estudo são ferramentas de ensino utilizadas na Administração, que encontram alinhamento com a aplicabilidade dessa Ciência. De acordo com Rigo, Nascimento e Brandão (2018), os casos de estudo têm relevância na prática de ensino pois antecipam dilemas organizacionais que serão enfrentados pelos estudantes no decorrer de sua vida profissional. São ferramentas de apoio aos docentes da área e servem como alternativa para variação da forma de apresentação de conteúdos ao longo da disciplina e enriquecimento do processo de aprendizado.

Alinhado a esses objetivos, esse trabalho apresenta um caso de estudo baseado em um caso real, o qual expõe o contexto e os desafios do processo de internacionalização de uma empresa americana de sementes agrícolas, especificando as etapas adotadas para a entrada e consolidação no mercado do Brasil. $O$ assunto é relevante para a prática de ensino pois internacionalização é uma importante estratégia de transformação para firmas (PAUL; SANCHEZ-MORCILIO, 2019) e as mudanças das últimas décadas a partir do uso de tecnologias digitais tem dado ênfase à importância do estudo de negócios internacionais. Utilizou-se para a discussão teórica e respostas às questões discutidas conceitos oriundos das Teorias de Internacionalização, em especial o modelo de Uppsala, com foco no gradualismo e modos de entrada em novos países. O modelo de Uppsala tem sido aplicado em diversos fenômenos dos negócios internacionais contemporâneos e tem sido revisada ao longo dos anos para abranger os avanços e mudanças nas práticas e nas pesquisas na área de negócios internacionais (COVIELLO; KANO; LIESCH, 2017).

O caso de estudo está organizado da seguinte forma: apresentação do caso e notas de ensino. Na apresentação do caso são expostas as informações sobre o histórico da empresa, características do mercado-alvo do processo de internacionalização e apresentação do 
cenário atual do mercado de sementes agrícolas no Brasil. As notas de ensino são organizadas em sinopse, questões para discussão, solução das questões e metodologia e dinâmicas sugeridas para aplicação em sala de aula.

\section{CASO DE ENSINO}

Em meados do verão de 1965, na cidade de Monteblanc, Estados Unidos, as plantas de milho já estavam altas nas unidades experimentais das estações de pesquisa da empresa Sementys. Quase que diariamente, automóveis chegavam para trazer visitantes de longe - do México, Japão, Extremo Oriente - que iam até o local para aprender sobre o 'ouro amarelo': a cultura do milho, recurso nutricional essencial para o mundo. Os visitantes chegavam à cidade, que é o lar da empresa Sementys, líder no setor de sementes para o agronegócio na América do Norte. Naquele ano, a empresa foi líder do setor em seu país, responsável por 30\% das sementes plantadas, e percebeu que seus produtos poderiam ser vendidos a clientes de todas as partes do mundo.

A sólida reputação da empresa baseia-se em grande parte em seu fundador, John Mayer, um jovem pesquisador que iniciou um programa de produção de sementes melhoradas de milho no quintal de sua propriedade, em 1915. Engenheiro agrônomo de formação, percebeu em suas experiências que os milhos produzidos a partir de melhoramento genético das sementes não tinham qualidades estéticas, mas sua produtividade era excepcional. Mudou o conceito de hibridismo, que antes era visto negativamente pelos produtores como 'mestiçagem', introduzindo o conceito de 'vigor híbrido', no qual a produtividade era mais importante do que a estética.

John acreditava que o aumento do potencial de rendimento de milho baseava-se na hibridização, ou endogamia, e no cruzamento de diferentes variedades de plantas de milho para produzir uma semente mais saudável, durável e com maior produtividade. Nesta época, a hibridação de milho estava ainda na fase de testes. A prática comum era os fazendeiros simplesmente salvarem as sementes de uma colheita e usá-las para plantar no ano seguinte. John estava convencido que cultivar milho da semente híbrida era o negócio do futuro e que havia um vasto mercado para o produto, uma vez que os agricultores poderiam produzir mais e melhor.

As sementes desenvolvidas com a nova tecnologia tiveram excelente aceitação no mercado americano. De perfil prioritariamente agrícola de monocultura, o país foi o ambiente perfeito para a continuidade do desenvolvimento da tecnologia genética e crescimento econômico da empresa. Já com domínio sob o mercado da América do Norte e com interesse em melhorar a produtividade de alimentos em nível mundial, os gestores da Sementys acreditavam que a empresa deveria aplicar seus conhecimentos genéticos em todas as oportunidades. Não havia dúvida sobre a necessidade no longo prazo de maior produtividade e eficiência na agricultura global. $O$ crescimento da população e o desenvolvimento econômico de muitos países iriam aumentar a demanda por alimentos no futuro próximo. Essa percepção levou a empresa a expandir suas operações para outros países na década de 1970.

\section{Semeando o Brasil}

O Brasil é, historicamente, importante produtor agrícola. O agronegócio é uma das bases da economia do país desde os tempos de sua colonização, inicialmente com a produção de café e cana de açúcar. As políticas governamentais no setor agrícola das décadas de 1960 e 1970 concentravam-se na concessão de crédito subsidiado e, a partir da década de 1980, na política de garantia de preços mínimos. A agropecuária também era peça importante no 
cenário econômico do país. O Brasil possui área agrícola de aproximadamente 60 milhões de hectares, que representa aproximadamente $7 \%$ do total da área do país, clima favorável, importante produção agropecuária e incentivos econômicos do governo. Esse conjunto de fatores fizeram o país ser escolhido para o ingresso da empresa Sementys na América do Sul, sendo definido como o país de maior potencial entre os países averiguados pela empresa.

Na safra de 1970, a Sementys iniciou a exportação de sementes para o Brasil. Nessa primeira etapa, as sementes eram vendidas a uma empresa brasileira, a Agroseed, do estado do Rio Grande do Sul, que as revendia aos produtores nacionais. Em um segundo momento, com o aumento do volume de sementes vendidas para a Agrossed, houve desenvolvimento de parceria entre as duas empresas, a qual visava à comercialização e distribuição de sementes para agricultores brasileiros, com objetivo de alcançar um maior número de produtores, em diferentes estados, incluindo estados do sudeste e centro-oeste do país.

Através dessa parceria, foram introduzidas sementes de milho de ciclo precoce, porte baixo e de maior potencial genético, desenvolvidas nos Estados Unidos, dando início a uma nova fase da agricultura de milho no Brasil. Nessa época, a produção de sementes híbridas no Brasil era discreta e a tecnologia utilizada, assim como os resultados, eram inferiores aos das sementes norte-americanas. Para iniciar a venda no país, foram introduzidas sementes desenvolvidas para o clima norte-americano, sem adaptações ao clima local e características do solo em um primeiro momento.

A parceira comercial foi tão profícua que, poucos anos depois, foi anunciada a formação da empresa Agroseed-Sementys, uma joint venture formada pelas duas empresas. A parceira pautava-se pelo fornecimento de tecnologia genética de grãos pela Sementys e o conhecimento do mercado comercial, clientes e distribuição no país pela Agroseed.

$\mathrm{Na}$ década de 1970, a pesquisa, desenvolvimento de produtos e o processo de beneficiamento das sementes eram realizados nos laboratórios e unidades produtivas localizados na América do Norte. Depois de ensacados, os produtos seguiam de navio pelo mar até os portos brasileiros, para entrega nos galpões de armazenamento da joint venture. A Agroseed-Sementys era responsável pela comercialização e distribuição dos produtos, além de monitorar junto aos agricultores o desempenho das sementes e da produção de milho.

Com a grande aceitação do produto pelos produtores brasileiros, o centro de pesquisa começou a desenvolver sementes específicas para o clima e solo do país. Naquela época, a produção de milho no Brasil era caracterizada pelo plantio de verão, durante o período chuvoso que ocorre no final de agosto, na região sul, até os meses de outubro e novembro, no Sudeste e Centro-Oeste.

No final da década de 1970, foi iniciada a plantação extemporânea e sem irrigação, nos estados de São Paulo, Paraná, Goiás, Mato Grosso e Mato Grosso do Sul. O milho era semeado após a colheita precoce da soja e esse tipo de plantação, chamada de safrinha, foi o propulsor da produção de milho no país. O milho da safrinha era destinado, em sua grande parte, para alimentação dos animais criados pelos suinocultores e avicultores daquela região. Para o produtor, apresentava-se como um bom negócio pois, fora da época tradicional de plantio, as sementes utilizadas apresentavam valor mais baixo e o preço de venda do produto final era superior. A introdução das sementes híbridas em solo brasileiro ofereceu impacto direto na produtividade das plantações. De acordo com dados da Embrapa - Divisão de milho e sogro (2017), desde 1972, a área total de produção mantém-se estável, enquanto a produção e a produtividade tiveram crescimento exponencial.

Em 1984, com o mercado de sementes de milho aquecido no Brasil, a Sementys adquiriu o controle acionário da empresa, que passou a denominar-se simplesmente 
Sementys, passando a ter um elevado grau de envolvimento com o mercado brasileiro, visto que já havia adquirido muito conhecimento. Nessa época, iniciou o processo de beneficiamento de sementes e pesquisa no país, construindo estações de beneficiamento e estações de pesquisa no Rio Grande do Sul e em Goiás. Com o aumento da importância da safrinha na produção brasileira, em 1989 a estação de pesquisa do Rio Grande do Sul foi transferida para o Paraná, para dar foco à pesquisa de desenvolvimento de grãos adequados para as características desse tipo de plantação.

No final da década de 1990, a empresa entrou no mercado de sementes de soja, com a aquisição de um programa de melhoramento de sementes da soja brasileira. Construiu outra unidade no estado de Goiás, própria para o beneficiamento de sementes de soja. Nos anos 2000, houve investimento na área de logística da empresa, com instalação de centros de distribuição em diversos estados brasileiros e desenvolvimento de nova embalagem para entrega de sementes em jumbo bags (embalagens de uma tonelada).

\section{E nos dias de hoje...}

Atualmente, a cultura do milho ocupa posição de destaque no cenário nacional, com área aproximada de 15 milhões de hectares cultivados no Brasil e produção de 65 milhões de toneladas anuais. Aproximadamente $70 \%$ de todo o milho produzido é destinado à fabricação de rações para o consumo animal, alimentando principalmente os setores da avicultura e suinocultura do país. O Brasil é o terceiro maior produtor e o segundo maior exportador mundial de milho.

O milho é o cereal de maior volume de produção no mundo, com aproximadamente 960 milhões de toneladas. Estados Unidos, China, Brasil, México, Indonésia e Índia são, nessa ordem, os maiores produtores, representando $70 \%$ da produção mundial. Nos dias de hoje, aproximadamente $97 \%$ das sementes utilizadas nas plantações são sementes híbridas. Esse dado surpreende até mesmo os mais otimistas do setor.

Devido a estes expressivos números do setor, a empresa continua seu processo de expansão internacional e os herdeiros de John Mayer, hoje à frente da empresa, estão analisando, juntamente com a equipe de inteligência, qual o próximo país a ser explorado. Uma das opções é o Paraguai, localizado na América do Sul, vizinho do Brasil. A partir da subsidiária brasileira, desde 2012, a Sementys tem exportado sementes híbridas para o Paraguai, as quais são revendidas por empresas locais. Os produtos têm tido boa aceitação naquele mercado e haveria oportunidade de ampliar sua participação. Porém, o solo e o clima paraguaio demandariam investimento no desenvolvimento de sementes adaptadas para as condições do país. Por outro lado, o país está localizado na América do Sul, subcontinente no qual a empresa já tem operações e experiência com a cultura.

A empresa passa pelo dilema de decidir para qual país deve continuar sua expansão. Outro dilema enfrentado é a opção de mobilizar ativos e recursos para a entrada em novo país, ou optar por estratégias sem mobilização de recursos. Também deve considerar a disponibilidade de ativos das firmas locais para firmar as parcerias necessárias. Todas essas questões exigem que a empresa avalie internamente seus recursos, estratégias e capacidades, além de analisar o ambiente e contexto econômico, de legislação, político e de negócios no país em que pretende iniciar suas operações. Essa complexa teia de informações deve ser analisada com cautela pela empresa, na busca da melhor decisão.

Antes de implementar a nova expansão, a empresa busca entender melhor como ocorreu seu processo de entrada no Brasil, buscando aprimorar as técnicas de negócios e otimizar seus investimentos. Nesse contexto, são perguntas importantes: Como foi o processo 
de entrada da Sementys em solo brasileiro? Quais etapas foram realizadas? O que a empresa aprendeu com a entrada no Brasil? A entrada no Paraguai é um processo similar ao processo de entrada no Brasil? Essas são algumas das perguntas para serão respondidas na próxima etapa do nosso estudo.

\section{NOTAS DE ENSINO}

\subsection{SINOPSE}

Este caso de estudo aborda a história da internacionalização de uma empresa norteamericana de sementes agrícolas híbridas e sua entrada no mercado brasileiro, contextualizada a partir do desenvolvimento da agricultura do milho no país. $\mathrm{O}$ caso descreve o processo e as etapas de internacionalização vivenciadas pela empresa. Para a discussão desse caso, utilizou-se o embasamento de conceitos oriundos da teoria de internacionalização de Uppsala, identificando a aplicação dos principais conceitos da teoria no caso prático, com foco no gradualismo, sendo que entrou no país a partir de exportação direta, após fixou um agente para facilitar a comercialização, com o qual posteriormente estabeleceu uma joint venture. E após amadurecimento e conhecimento deste mercado, passou a um nível maior de envolvimento, sinalizado a partir da aquisição da empresa.

No caso da internacionalização da Sementys para o Brasil, a cronologia do processo inicia-se na década de 1970, quando a empresa começa a exportar sementes para o país latino, as quais eram revendidas pela Agroseed, localizada no Rio Grande do Sul. Logo em seguida, as empresas firmaram uma parceria para a distribuição de sementes, com o objetivo de atingir mais produtores, inclusive de estados como São Paulo e Mato Grosso.

Com o sucesso da parceria comercial, poucos anos depois, a empresa norte-americana e a brasileira uniram-se em uma joint venture, a Agroseed-Sementys, responsável pela comercialização e distribuição dos produtos e por monitorar, junto aos agricultores, o desempenho das sementes e da produção de milho. Foi em 1984 que a Sementys adquiriu o controle acionário da empresa, ocasião em que construiu estações de beneficiamento e estações de pesquisa no Rio Grande do Sul e em Goiás. Atualmente, a empresa estuda o processo de internacionalização para o Paraguai, para onde já iniciou a exportação de sementes.

\subsection{QUESTÕES PARA DISCUSSÃO}

As questões propostas para discussão com base no texto apresentado são as seguintes:

a) O processo de internacionalização da Sementys no Brasil pode ser explicado por qual teoria? Com base em qual(is) acontecimento(s) essa teoria pode ser evidenciada?

b) Quais tipos de modos de entrada podem ser identificados no processo de entrada da Sementys no Brasil?

c) Qual o impacto da vinda da multinacional para o Brasil sobre as concorrentes nacionais e suas possíveis consequências econômicas?

d) No caso da empresa Sementys, como os conceitos de conhecimento e comprometimento, assim como distância psíquica (JOHANSON; VAHLNE; 1977), podem ser considerados e aplicados na entrada da empresa no Paraguai?

e) Considerando o contexto atual global de negócios com uso intensivo de novas tecnologias (indústria 4.0,5G, internet das coisas, blockchain, etc.), quais desafios que empresas que buscam internacionalização podem encontrar? 
f) Segundo Fernandes e Rocha (2005), a distância psíquica percebida pelos brasileiros em relação aos demais países segue a ordem Argentina, México e Portugal (menos estrangeiro), e Japão e China (os mais distantes). A partir da teoria de Upsalla, discorra sobre essa constatação, exemplificando brevemente sua resposta com cases de empresas brasileiras que passaram pelo processo de internacionalização.

\subsection{SOLUÇÃO DAS QUESTÕES}

a) Qual teoria explica o processo de internacionalização da Sementys no Brasil? Com base em qual(is) acontecimento(s) pode ser evidenciada esta teoria?

Impulsionada por um mercado promissor e detentora de uma nova tecnologia para o cultivo do milho, a Sementys iniciou seu processo de internacionalização para o Brasil de forma gradual. Desta forma, pode-se explicar que o processo de internacionalização segue a linha proposta pelo modelo de Uppsala.

O modelo de Uppsala foi desenvolvido na década de 1970 por Johanson e Wiedersheim-Paul (1975), ao analisarem como as firmas suecas Sandvik, Atlas, Copco, Facit e Volvo realizavam a internacionalização de seus negócios. É considerado uma ferramenta de análise em nível de firma, ou seja, micronível (VAHLNE; JOHANSON, 2017). O modelo propõe que a internacionalização da empresa é um processo dinâmico de aprendizagem, no qual a empresa investe recursos gradualmente e adquire conhecimentos sobre determinado mercado internacional de maneira incremental. Johanson e Vahlne (2009) relatam que o modelo de Uppsala prevê que a internacionalização ocorre gradativamente, passando por quatro etapas: atividades de exportação, atividades de exportação por meio de representantes, escritórios de vendas e produção local.

De acordo com Hilal e Hemais (2003) e VahIne e Johanson (2017), o modelo de Uppsala define a firma internacional como uma organização caracterizada por processos cumulativos de aprendizagem. Andersen (1993) descreve, ainda, que o compromisso da organização internacional com o novo mercado é composto pela quantidade de recursos comprometidos e o grau de comprometimento. Nesse contexto, conforme adquire-se maior conhecimento do mercado, maior são os recursos aplicados pela organização que, gradativamente, aumenta seu comprometimento com o mesmo. O modelo pressupõe que o risco e a falta de confiança e conhecimento seriam fatores de restrição da internacionalização. Assim, o conhecimento experimental geraria confiança e consequente comprometimento, superando as restrições (DOW; LIESCH; WELCH, 2017).

Porém, Johanson e Wiedersheim-Paul (1975) reconhecem que nem todas as empresas seguem os quatro estágios da cadeia de estabelecimento, podendo avançar no processo sem necessariamente realizar todas as etapas propostas. Cada etapa alcançada fornece certo grau de conhecimento do mercado, que permite avanço para etapas mais complexas e que envolvem maior alocação de recursos e, consequentemente, maiores riscos.

No caso apresentado, ficam evidenciadas algumas etapas percorridas pela Sementys até sua instalação efetiva no Brasil: exportação para o mercado brasileiro por meio de parceria com empresa local, joint venture e aquisição da empresa que foi sua parceira no início das atividades em solo brasileiro. Outro aspecto que pode ser correlacionado ao modelo de Uppsala é que a organização primeiramente desenvolve-se no seu mercado doméstico, sendo a internacionalização consequência de uma série de decisões incrementais. Esse fato pode ser constatado no caso exposto: após atingir a liderança no seu mercado doméstico, a Sementys iniciou sua expansão para o Brasil. 
A distância psíquica é um fator relevante na análise de processos de internacionalização, e trata-se da distância percebida por indivíduos ou grupos em relação a um país em particular (BEUGELSDIJK; AMBOS; NELL, 2018). O modelo de Uppsala considera que a distância psíquica exerce influência significativa na escolha da localização geográfica e nos caminhos de internacionalização (JOHANSON; VAHLNE, 1977). Johanson e WiedersheimPaul (1975) relatam que as empresas geralmente iniciam sua internacionalização para países com menor distância psicológica, o que não é evidenciado no caso da vinda da Sementys ao Brasil. Estados Unidos e Brasil possuem diferenças de idioma, leis e normas sociais, fatores que de acordo com Paul e Sanchez-Morcilio (2019), aumenta a distância psíquica entre os dois países. Porém, pode-se argumentar que no segmento específico que está em análise, o agronegócio, os países são semelhantes, pois possuem grande área territorial, solo propício para o cultivo, potencial para crescimento e a agroindústria é base econômica desses países.

b) Quais os modos de entrada que a Sementys utilizou para sua internacionalização no Brasil?

Os modos de entrada no mercado externo são estratégias para organizar e conduzir transações comerciais com países estrangeiros (DE VILLA; RAJWANI; LAWTON, 2015). A escolha de uma estratégia de inserção em mercados internacionais por uma organização deve levar em conta os objetivos desejados pela organização e o conhecimento do mercado em que se pretende atuar (SILVA; CABRAL; OLIVEIRA, 2008). Conforme Dunning (1988), a característica do país de origem, os aspectos legais e políticos, os riscos existentes e as perspectivas de crescimento influenciam diretamente a escolha da forma de entrada no país que se pretende estabelecer relações comerciais. Questões ligadas ao ambiente interno da organização também devem ser consideradas na escolha da estratégia. Dimensões estratégicas do negócio, como a capacidade administrativa e tecnológica da empresa são fatores relevantes que podem influenciar o sucesso ou insucesso da estratégia.

Dunning (1993) aponta para quatro motivos para a internacionalização: procura de mercado, de recursos, de eficiência e de recursos estratégicos, sendo que as estratégias e os modos de entrada apresentam uma diferente relação de custo e benefício (ANDERSSON; GATIGNON, 1986). Outra questão importante é que a internacionalização permite à firma não só capitalizar oportunidades em novos mercados, mas também a defender sua posição no mercado global em relação à demais competidores com estratégias similares (PAUL; SANCHEZ-MORCILIO, 2019). A definição do modo de entrada no mercado externo pode ser considerada uma das decisões mais complexas na internalização (AGARWAL; RAMASWAMI, 1992), pois é determinante sobre a estrutura organizacional que a empresa adotará ao entrar inicialmente no mercado e outro país (HOLLENDER; ZAPKAU; SCHWENS, 2016).

Quanto às principais abordagens aos modos de entrada, destacam-se três: gradual, baseada nas imperfeições do mercado e por meio da rede de relacionamentos. Johanson e Vahlne (2009), propõem um modelo em que os modos de entrada seguem um padrão sequencial gradual, no qual o comprometimento amplia-se com o maior conhecimento do mercado pretendido. Os autores concluem, a partir de seus estudos, que as empresas iniciam suas atividades além do mercado doméstico por meio de exportação, seguido por jointventures e, à medida que se tornam mais experientes ou com maior conhecimento sobre outros mercados, passam a ter operações próprias no exterior.

A segunda abordagem argumenta que a internacionalização das multinacionais (EMNs) é influenciada por mercados imperfeitos (DUNNING, 1988). Nesses casos, a organização busca explorar a imperfeição dos mercados por meio de vantagens específicas da empresa. A terceira abordagem baseia-se no entendimento de que internacionalização da 
firma não é um processo isolado e na ideia que os relacionamentos inter-empresas são fontes de informação de oportunidades e influenciam as opções estratégicas das empresas (JOHANSON; MATTSON, 1988; JOHANSON; VAHLNE, 2009), caracterizando as redes relacionais.

A partir das principais abordagens, identificam-se seis modos de entrada: exportações diretas e exportações indiretas, licenciamento, joint ventures, alianças estratégicas, investimentos greenfield e aquisições, sendo que a adequação do modo de entrada dependerá das motivações que a empresa possui para cada país onde se estabelece. Os modos de entrada podem demandar aporte de capital e investimento no país de destino ou não (DE VILLA; RAJWANI; LAWTON, 2015). São exemplos de modos que demandam capital joint ventures, participações, aquisições e greendfield, enquanto estratégias por meio de exportação direta, exportação por meio de distribuidor, franchises, acordos de licenciamento são exemplos de estratégias que não demandam investimentos (HOLLENDER; ZAPKAU; SCHWENS, 2016). O primeiro grupo demanda disponibilidade e comprometimento de recursos, mas facilitam a proximidade com o país de destino e seus consumidores. Já, o segundo grupo permite maior flexibilidade à firma, exigindo menor aporte de recursos, mas em contrapartida dificulta a proximidade e o monitoramento dos mercados (HOLLENDER; ZAPKAU; SCHWENS, 2016).

As exportações podem ocorrer direta ou indiretamente (ROOT, 1994). Na exportação indireta, o fabricante não precisa dominar as normas do comércio internacional, uma vez que o negócio é realizado por meio de um intermediário. Já na situação de exportação direta, fica sob responsabilidade da empresa produtora o processo de exportação e, assim, necessita obter conhecimentos específicos relacionados aos negócios internacionais e ao mercado em que está realizando as transações.

O licenciamento é um arranjo contratual em que uma empresa (ou licenciador) torna disponível um ativo para uma outra empresa (ou licenciado), em troca de royalties, honorários de licenciamento ou alguma outra forma de remuneração (FERRELL; HARTLINE, 2000). Já o joint venture ocorre quando duas empresas se unem estabelecendo uma nova entidade jurídica autônoma separada das duas anteriores que continuam a operar em seus respectivos países. Ou seja, é criada uma empresa, com vida jurídica própria (SUEN; KIMURA, 1997).

Alianças estratégicas, conforme Gulati (1998), também são arranjos empresariais, porém com foco ao desenvolvimento tecnológico, de produtos ou de serviços em conjunto e de forma voluntária. O modo de entrada Greenfield consiste na construção de uma subsidiária produtiva desde o seu início, utilizando-se os recursos e conhecimento do investidor, ele deverá se preocupar com a compra do local das futuras instalações, a contratação e treinamento dos empregados, utilizando a experiência gerencial da empresa matriz. Além disso, deverá transferir tecnologias de produção, conhecimento e capital (BROUTHERS; BROUTHERS, 2000). Por fim, a estratégia de entrada por meio de aquisições caracteriza-se como um tipo de investimento direto com a aquisição de plantas industriais ou estruturas de negócios, no qual ocorre a transferência de conhecimentos e habilidades de uma organização para um país estrangeiro sem a ajuda de parceiros (HILL, 1991).

No caso da Sementys, o processo de internacionalização para o Brasil teve início com a exportação do produto por meio de um agente exportador. O mercado local apresentou aceitação ao produto e em condições favoráveis de negócio, a parceria passou a joint venture, evoluindo para processo de aquisição. A atividade de exportação observada no caso descrito identifica-se ao modelo de Uppsala, que considera o comprometimento com o mercado externo a partir do aprendizado obtido com o ganho de experiência e conhecimento. Como 
um ponto de partida, foi realizada uma aproximação com o país para o qual se pretendia ampliar a atuação, diminuindo assim a distância física, definida por Vahlne e Johanson (2017) como a "soma de fatores que interferem no fluxo de informações entre mercados, como a diferença entre línguas, educação, práticas de negócios, cultura, desenvolvimento industrial, dentre outros" (p. 24).

Em seguida, a parceria que a Sementys realizou com a representada no Brasil, para a exportação das sementes, configura-se em um caso de exportação direta, ou seja, quando a venda é feita diretamente entre o fabricante e o distribuidor ou intermediário no país importador. Nessa etapa, segundo Forner (1999), o exportador deve realizar pesquisa mercadológica prévia, contatos e avaliação dos riscos, fechamento do negócio, preparação de mercadoria e embarque.

Em etapa posterior, a Sementys avaliou que detinha o conhecimento necessário para ampliar sua atuação no mercado internacional. Assim, optou pela criação de joint venture com a Agroseed, formando assim a Agroseed-Sementys. Nessa estratégia, segundo Keegan e Green (1999), os sócios compartilham a posse e os riscos e tem a capacidade de combinação de diferentes pontos fortes da cadeia de valor, assim como a suplementação dos pontos fracos.

Para os autores, alguns pontos devem ser considerados para que se garanta o sucesso da joint venture, como a) escolha do melhor parceiro para estabelecimento do negócio; b) o estabelecimento de objetivos claros desde o começo do acordo; e c) a redução das diferenças culturais entre os parceiros. Percebe-se que os critérios citados acima foram atendidos no caso da Sementys, uma vez que a empresa escolheu um parceiro já conhecido, reduzindo assim a chance de conflitos de gestão ou estratégicos.

O processo de internacionalização culminou na aquisição da Agroseed pela Sementys, a qual assumiu o controle acionário e manteve seu nome original. Entre as vantagens desse negócio, esteve a manutenção de todo o conhecimento sobre o negócio, incluindo canais de distribuição, fornecedores e tecnologia, mas sem a necessidade de dividir o controle com uma segunda organização.

c) Qual o impacto da vinda da multinacional para o Brasil sobre as concorrentes nacionais e suas possíveis consequências econômicas?

No período em que a Sementys iniciou suas atividades no Brasil, a produção de sementes de milho por empresas nacionais era modesta e a pesquisa e desenvolvimento de novos produtos com pouca expressão. No ano de 1973 surge a Empresa Brasileira de Pesquisa Agropecuária (Embrapa), vinculada ao Ministério da Agricultura, Pecuária e Abastecimento (Mapa), com o objetivo de desenvolver um modelo de agricultura e pecuária tropical genuinamente brasileiro, em uma tentativa de superar as barreiras que limitavam a produção de alimentos, fibras e energia no país.

Segundo Guimarães (2000), a empresa nacional brasileira, pelo escasso apoio estatal à pesquisa privada, tende a investir pouco em pesquisa tecnológica. Desta forma, entende-se que Sementys, empresa estrangeira multinacional de grande porte, detinha capacidade organizacional, tecnológica e financeira maior do que as empresas nacionais do mesmo setor. Ou seja, encontrava-se em vantagem competitiva frente às empresas brasileiras. Pivelo (2011) observa que a entrada de fortes concorrentes gera pressão sobre as empresas nacionais que estavam defasadas tecnologicamente. Esse processo pode resultar na saída de empresas nacionais do mercado.

Em uma perspectiva econômica, Hymer (1983) destaca como lado negativo da instalação de empresas multinacionais em mercados menos desenvolvidos, tal como o caso 
da Sementys no Brasil, os problemas criados no mercado produtivo interno. A instalação da empresa estrangeira, por sua dimensão e acesso ao mercado internacional, ocasiona condições para o surgimento de estruturas de oligopólio no mercado e, portanto, para a geração e remessa de lucros e diminuição da poupança disponível para ampliar a capacidade instalada do país.

Tal teoria se confirma posteriormente, através de estudos de Londres e Almeida (2009) sobre as estratégias de concentração econômica e de monopólio tecnológico que marcam a trajetória das grandes empresas do setor sementeiro desde a década de 70 até então. Essa trajetória se traduz em um rápido processo de integração nacional dos mercados de sementes, que tem se efetivado notadamente através da fusão (ou da inviabilização econômica) de empresas regionais, em prejuízo de um sistema capilarizado de mercados regionais mais vinculados às expressões das economias e da biodiversidade local. Como consequência dessa evolução, o mercado de sementes se integra progressivamente ao complexo agroindustrial, ao mesmo tempo em que se desloca do ambiente agrícola para se subordinar aos interesses do componente industrial.

De acordo com Guimarães (2009), esse movimento de desnacionalização da economia recebe críticas por acarretar a transferência para o exterior de centros de decisão da atividade econômica. Ou seja, as decisões de investimento, de exportação, de importação, de uso de tecnologia, de emprego passam a ser tomadas não apenas em função das características e da situação da sociedade onde atuam as filiais das empresas multinacionais, mas sim, em função de sua estratégia global.

Por outro lado, a entrada de empresas multinacionais em países emergentes pode beneficiar as firmas locais. O modelo proposto por Hennart (2009) considera que a entrada de uma empresa estrangeira em mercado externo envolve a agregação de recursos intangíveis pelo investidor estrangeiro com ativos complementares de atores locais e que o modo de entrada escolhido deverá maximizar o ganho conjunto das duas partes. Assim, as empresas locais são necessárias e determinantes para as operações de empresas estrangeiras, ocorrendo relação de agregação de valor para ambas em busca de melhor desempenho (HENNART; SHENG; PIMENTO, 2015). Nesse contexto, argumentam que nessa relação as empresas locais de países emergentes podem ser beneficiadas com transferência de tecnologia e conhecimento de gestão (KHAN; LEW; SINKOVICS, 2015).

d) No caso da empresa Sementys, como os conceitos de conhecimento e comprometimento (JOHANSON; VAHLNE, 1977), podem ser considerados e aplicados na entrada da empresa no Paraguai?

A partir da teoria de Upsalla, Johanson e Vahlne (1977) apresentam os conceitos de: conhecimento e comprometimento. Conhecimento é o que se sabe sobre o mercado-alvo, tanto aquilo que é passível de transmissão, quanto o que pode ser aprendido somente por meio da experiência. Já comprometimento, refere-se aos recursos investidos em um determinado mercado internacional. Esses dois conceitos também interagem com outros dois aspectos: decisões de comprometimento e atividades correntes. O primeiro refere-se às decisões de investimento em alternativas já testadas no passado, o que contribui para reduzir o grau de incerteza nas operações internacionais. O segundo, refere-se às operações atuais da empresa no mercado-alvo, as quais constituem a principal fonte de conhecimento sobre esse mercado.

No caso da Sementys, a empresa estuda o mercado internacional para a tomada de decisão sobre onde expandir seu negócio, tendo o Paraguai como candidato de maior 
potencial. Por meio da subsidiária brasileira, a Sementys já realiza a exportação de sementes híbridas em parceria com empresas locais paraguaias, o que segundo a Teoria de Upsalla, vem ao encontro do conceito de conhecimento. Em primeira instância, o conhecimento sobre o mercado local pode ser transmitido por meio das parceiras locais, embora essa dinâmica limite o conhecimento que pode ser adquirido somente por meio da experiência. Esses fatores devem ser analisados em paralelo com as atividades recorrentes no mercado-alvo (ou seja, exportação), as quais já sinalizam à Sementys sobre a necessidade de adaptar os produtos geneticamente modificados às condições climáticas e de solo do Paraguai.

Com cem anos de atuação (a empresa iniciou as primeiras pesquisas em 1915), a Sementys também possui decisões de comprometimento nas quais se basear, já que domina o processo de internacionalização para o Brasil, podendo recorrer a alternativas já testadas no passado. Seguindo o modelo que já domina, o passo natural para a Sementys seria a formação de uma joint venture com uma de suas parceiras paraguaias, mas para isso, necessita que a mesma possa disponibilizar ativos próprios. Como ocorreu no Brasil com a Agrossed, esta parceria pode pautar-se pelo fornecimento de tecnologia genética de grãos pela Sementys, e pelo conhecimento do mercado comercial, clientes e distribuição pela parceira paraguaia. Se optar por recorrer a essa alternativa, a Sementys firma seu comprometimento de mercado, investindo, portanto, todos os recursos necessários para a consolidação nesse novo mercado internacional.

e) Considerando o contexto atual global de negócios com uso intensivo de novas tecnologias (indústria 4.0, 5G, internet das coisas, blockchain, etc.), quais desafios que empresas que buscam internacionalização podem encontrar?

Vahlne e Johanson (2017) afirmam que o contexto internacional de de negócios está passando por uma mudança radical devido às inovações na era da informação. As mudanças nos mercados e relações de negócio internacionais ocorridas nas últimas décadas resultaram em novas práticas e desafios para os negócios internacionais. Em especial, o uso de novas tecnologias digitais que facilitam o fluxo de informação, conhecimento, mobilidade (COVIELLO; KANO; LIESCH, 2017), que possibilitaram novos modelos de negócios disruptivos e globais (exemplo: Uber, Airbnb, Blablacar). Vahlne e Johanson (2017) em artigo publicado no 40을 aniversário do modelo de Uppsala enfatizam a necessidade de pensar os negócios globalmente, além da firma, para adaptar-se ao novo contexto dos negócios internacionais. Propõem que haja orientação para processos (não mais em estruturas), para redes e trocas (no lugar de posições solitárias em focadas na produção), postura proativa e empreendedora e estrutura descentralizada.

Os fenômenos tecnológicos modernos causam uma distribuição das vendas e das operações diferenciada, em especial resultante de vendas pela internet, e resultam na necessidade de desenvolver novas formas de se fazer negócios internacionais. Soluções de tecnologia, cadeia de suprimentos e logística podem demandar o desenvolvimento de capacidades das firmas, em especial de transação. Paul e Sanchez-Morcilio (2019) sugerem que os processos de internacionalização descritos pela literatura não têm acompanhado as mudanças aceleradas do mercado internacional, em especial o crescimento e protagonismo das empresas nascidas globais.

Além desses impactos, questões ligadas à regulação setoriais e governamentais e tributação têm sido discutidas em diferentes países e as empresas podem ter que lidar com diferentes contextos regulatórios de acordo com o país que opera. 
f) Segundo Fernandes e Rocha (2005), a distância psíquica percebida pelos brasileiros em relação aos demais países segue a ordem Argentina, México e Portugal (menos estrangeiro), e Japão e China (os mais distantes). A partir da teoria de Upsalla, discorra sobre essa constatação, exemplificando brevemente sua resposta com cases de empresas brasileiras que passaram pelo processo de internacionalização.

Segundo Johanson e Wiedersheim-Paul (1975), as empresas tendem a iniciar o processo de internacionalização em países considerados culturalmente próximos, diminuindo assim a distância psíquica e, consequentemente, o grau de incerteza por meio da solução de problemas em ambientes similares. Nesse contexto, o nível de desenvolvimento dos países, o nível educacional, as práticas de negócios, e a linguagem, são alguns dos fatores a serem considerados. Apenas depois de adquirir mais experiência de atuação nos mercados estrangeiros, é que a empresa tende a abordar mercados psiquicamente mais distantes (JOHANSON; VALHNE; 1977). Segundo Tanure, Cyrino e Penido (2007), no entanto, apenas internacionalizar a partir de países culturalmente próximos, não é garantia de sucesso. Em muitos casos, segundo os autores, a proximidade estrutural dos mercados oculta a complexidade das adaptações necessárias e as dificuldades de colocá-las em prática.

Entre os exemplos que podem ser citados, estão a Havaianas, que iniciou seu processo de internacionalização em 1998, ao exportar seus produtos para a América Latina, utilizando as mesmas estratégias de preço e catálogo de produtos já utilizados no mercado nacional. Em 2007, dominando 75\% do mercado nacional e com exportações estabelecidas para parceiros em Nova York e Paris, a empresa abriu sua primeira loja monomarca em Manhattan. Como item do segmento de moda, o posicionamento das sandálias Havaianas nessas capitais foi considerado estratégico pela empresa, desconsiderando, portanto, fatores como nível de desenvolvimento econômico e barreira de idiomas, mas considerando a prática de negócios similar. Seguindo o processo de internacionalização, e após já dominar mercados psiquicamente mais próximos, a Havaianas instalou uma subsidiária de produção na China, fator determinante para a expansão da marca para países como Japão e Austrália (SILVA; SOUSA; FREYRE, 2010).

Outro exemplo que pode ser discutido é a Totvs, capital nacional líder no Brasil em software de gestão. A empresa iniciou seu processo de internacionalização por meio de franquias e filiais na América Latina (primeiramente em Buenos Aires, seguindo para Chile, Colômbia, Porto Rico, Paraguai e Uruguai), expandindo, subsequentemente, para Portugal, México e Angola, movimentos que exemplificam a proximidade cultural e de idioma. Focando em um público-alvo denominado "self-made men", a Totvs também apostava em mercados internacionais profícuos para pequenas e médias empresas, uma prática de negócios amplamente trabalhada no Brasil, e com a qual já possuía experiência (MORAES, 2012). 


\subsection{METODOLOGIA DO CASO E DINÂMICAS EM SALA DE AULA}

É sugerida a indicação de leituras suplementares, de acordo com a ênfase da disciplina e o contexto educacional (graduação ou pós-graduação). Assim, a revisão bibliográfica utilizada nas notas de ensino pode ser indicada aos estudantes como bibliografia de apoio.

O caso pode ser aplicado em uma aula cujo foco seja a discussão de aspectos de gradualismo na internacionalização, teoria de Uppsala, decisão sobre produto no processo de internacionalização e modos de entrada em mercados internacionais. Com duração de dois períodos, sugere-se a seguinte dinâmica:

1) Aquecimento - breve introdução sobre os assuntos a serem tratados e dinâmica da aula (10 minutos);

2) Apresentação de reportagem sobre milho híbrido - introdução do tema e do contexto empresarial (5 minutos)

(sugestão: https://www.youtube.com/watch?v=1vnqU2nAlJQ);

3) Leitura do caso em pequenos grupos (aproximadamente 15 minutos);

4) Discussão nos grupos e sistematização das principais conclusões para serem apresentadas ao grande grupo (30 minutos);

5) Apresentação dos grupos (5 minutos para cada grupo);

6) Sistematização das apresentações pelo docente e fechamento ( 25 minutos).

O caso também pode ser apresentado ao final de uma aula solicitando-se que os alunos realizem a tarefa de discussão e resposta das questões em grupo ou individualmente por meio de plataformas virtuais de ensino (Google Classroom ou Moodle). Cada aluno ou grupo de alunos (dependendo do tamanho da turma) pode ficar responsável pela discussão de uma das questões, sendo desafiado a buscar outros exemplos similares de internacionalização de empresas de áreas negócio diferente ou seguindo dentro da lógica do agronegócio.

\section{REFERÊNCIAS}

AGARWAL, S.; RAMASWAMI, S. Choice of foreign market entry mode: impact of ownership, location, and internalization factors. Journal of International Business Studies, New York, v. 23, n.1, p. 1-27, mar. 1992. DOI: https://doi.org/10.1057/palgrave.jibs.8490257.

ANDERSEN, O. On the internationalization process of firms: a critical analysis. Journal of International Business Study, Hampshire, v. 24, n. 2, p.209-232, jun. 1993. DOI: https://doi.org/10.1057/palgrave.jibs.8490230.

ANDERSON, E.; GATIGNON, H. Modes of foreign entry: a transaction cost analysis and propositions. Journal of International Business Studies, New York, v. 17, n. 3, p 1-26, set. 1986. DOI: http://doi.org/101057/palgrave.jibs.8490432.

BROUTHERS, K. D.; BROUTHERS, L. E. Acquisition or greenfield start-up? Institutional, cultural and transaction cost influences. Strategic Management Journal, v. 21, n. 1, p. 89-97, jan. 2000. DOI: https://doi.org/10.1002/(SICI)1097-0266(200001)21:1<89::AID-SMJ85>3.0.CO;28. 
COVIELLO, N.; KANO, L.; LIESCH, P. W. Adapting the Uppsala model to a modern world: Macro-context and microfoundations. Journal of International Business Studies, New York, v. 48, n. 9, p. 1151-1164, dez. 2017. DOI: https://doi.org/10.1057/s41267-017-0120-x.

DOW, D.; LIESCH, P.; WELCH, L. Inertia and Managerial Intentionality: Extending the Uppsala Model. Management International Review, v. 58, n. 3, p. 465-493, jun. 2018.

DOI: https://doi.org/10.1007/s11575-017-0340-0.

DUNNING, J. H. The eclectic paradigm of international production: a restatement and some possible extensions. In: CANTWELL, J. (ed.). The Eclectic Paradigm. London: Palgrave Macmillan, 2015. DOI: https://doi.org/10.1007/978-1-137-54471-1_3.

DUNNING, J.H. Multinational enterprises and the global economy. Reading: AddisonWesley, 1993.

EMBRAPA. Cultivo do milho: mercado e comercialização. Disponível em http://www.cnpms.embrapa.br/publicacoes/milho_7_ed/mercado.htm. Acesso em: 13 jun. 2016.

FERNANDES, M. G.; ROCHA, A. Measuring the psychic distance construct: a test of two data collection instruments. In: Encontro Anual da Associação Nacional dos Programas de Pósgraduação em Administração, 29., 2005, Brasília. Anais [...]. Brasília: ANPAD, 2005.

FERRELL, O. C.; HARTLINE, M. D. Estratégia de marketing. São Paulo: Atlas, 2000.

FORNER, C. Prospecção de mercado e marketing internacional. 2 ed. Porto Alegre: Sebrae/RS, 1999.

GUIMARÃES, S. P. Capital nacional e capital estrangeiro. Disponível em: http://www.scielo.br/scielo.php?script=sci_arttext\&pid=S0103-40142000000200011. Acesso em: 15 jun. 2016.

GULATI, R. Alliances and networks. Strategic Management Journal, v. 19, n. 4, p. 293-317, abr. 1998. DOI: https://doi.org/10.1002/(SICI)1097-0266(199804)19:4<293::AIDSMJ982>3.0.CO;2-M.

HENNART, J. F; SHENG, H. H.; PIMENTA, G. Local complementary inputs as drivers of entry mode choices: The case of US investments in Brazil. International Business Review, v. 24, p. 466-475, jun. 2015. DOI: https://doi.org/10.1016/j.ibusrev.2014.10.005.

HENNART, J. F. Down with MNE-centric theories! Market entry and expansion as the bundling of MNE and local assets. Journal of International Business Studies, New York, v. 40, p. 1432-1454, dez. 2009. DOI: https://doi.org/10.1057/jibs.2009.42.

HILAL, A.; HEMAIS, C. O processo de internacionalização na ótica da escola nórdica: evidências empíricas em empresas brasileiras. Revista de Administração Contemporânea 
(RAC), Curitiba, v. 7, n. 1, p. 109-124, jan/mar. 2003. DOI: http://dx.doi.org/10.1590/S141565552003000100006.

HILL, C. L. International business - competing in the global marketplace. Illinois: Irwin, 1991.

HOLLANDER, L.; ZAPKAU, F. B.; SCHWENS, C. SME foreign market entry mode choice and foreign venture performance: The moderating effect of international experience and product adaptation. International Business Review, v. 26, n. 2, p. 250-263, abr. 2017. DOI: https://doi.org/10.1016/j.ibusrev.2016.07.003.

HYMER, S. Empresas multinacionais: a internacionalização do capital. Rio de Janeiro: Edições Graal, 1983.

JOHANSON, J.; MATTSSON, L. G. Internationalization in industrial systems: A network approach. In: Strategies in Global Competition. London: Croom Helm, 1988.

JOHANSON, J.; WIEDERSHEIM-PAUL, F. The internationalization of the firm: four Swedish cases. Journal of Management Studies, v. 12, n. 3, p. 305-322, out. 1975. DOI: https://doi.org/10.1111/j.1467-6486.1975.tb00514.x.

JOHANSON, J.; VAHLNE, J. The internationalization process of the firm - A model of knowledge development and increasing foreign market commitments. Journal of International Business Studies, New York, v. 8, n. 1, p. 23-32, mar. 1977. DOI: https://doi.org/10.1057/palgrave.jibs.8490676.

JOHANSON, J.; VAHLNE, J. The Uppsala internationalization process model revisited: From liability of foreignness to liability of outsidership. Journal of International Business Studies, New York, v. 40, n. 9, p. 1411-1431, dez. 2009. DOI: https://doi.org/10.1057/jibs.2009.24

JOHANSON, J.; VAHLNE, J. The internationalization process of the firm - A model of knowledge development and increasing foreign market commitments. In: International Business. Routledge, 2017.

KEEGAN, W.J.; GREEN, M.C. Princípios de marketing global. São Paulo: Saraiva, 1999.

KHAN, Z.; LEW, Y. K.; SINKOVICS, R. R. International joint ventures as boundary spanners: technological knowledge transfer in an emerging economy. Global Strategy Journal, v. 5, p. 48-68, fev. 2015. DOI: https://doi.org/10.1002/gsj.1089.

LONDRES, F.; ALMEIDA, P. Impacto do controle corporativo no setor de sementes sobre agricultores familiares e sistemas alternativas de distribuição: estudo de caso do Brasil. A ASPTA - Agricultura Familiar e Agroecologia, 2009.Disponível em http://aspta.org.br/wpcontent/uploads/2011/05/Estudo-Sementes-ASPTA-WoW-AA-2009-FINAL. pdf. Acesso em: 16 jun 2015.

MORAES, S. T. A. A Internacionalização da Totvs. In: Encontro da ANPAD, 36., 2012, Rio de Janeiro. Anais [...]. Rio de Janeiro: ANPAD, 2012. 
PAUL, J.; SANCHEZ-MORCILIO, R. Toward a new model for firm internationalization: conservative, predictable, and pacemaker companies and markets. Canadian Journal of Administrative Sciences/ Revue Canadienne des Sciences de I'Administration, v. 36, n. 3, set. 2019. DOI: https://doi.org/10.1002/cjas.1512.

PIVELLO, S. O fluxo de investimentos externos para o Brasil na década de 90 e os impactos sobre a economia brasileira. Negócios em Projeção, Brasília, v. 2, n. 2, p. 12-32, jul., 2011.

RIGO, A. S; DO NASCIMENTO, I. R. T.; BRANDÃO, P. D. M. Tal Pai, Tal Filho? Decisões coletivas tendo em conta relações familiares. Administração: Ensino e Pesquisa, Rio de Janeiro, v. 19, n. 1, p. 135-160, jan-abr. 2018. DOI: http://doi.rog/135-

160. DOI:10.13058/raep.2018.v19n1.734.

ROOT, F. R. Entry strategies for international markets. New York: Lexington Books, 1994.

SILVA, L. N. N.; CABRAL, J. E. O.; OLIVEIRA, M. C. Estratégia de internacionalização de empresas: evolução e determinantes do canal de distribuição utilizado. In: COSTA, B. K.; ALMEIDA, M. I. R. Estratégia contemporânea: internacionalização, cenários e redes. Campinas, SP: Akademica, 2008.

SILVA, S. C.; SOUSA, M. J.; FREYRE, F. Understanding the internationalisation process of Havaianas: the important role of brand. Tourism \& Management Studies, Faro, n. 6, p. 118130, 2010.

SUEN, A, S.; KIMURA, H. Fusão e aquisição como estratégia de entrada (entre mode) no mercado brasileiro. Caderno de Pesquisas em Administração, v. 2, n. 5, p. 53-60, jul. 1997.

TANURE, B.; CYRINO, Á. B.; PENIDO, É. Estratégias de internacionalização: evidências e reflexões sobre as empresas brasileiras. In: FLEURY, A.; FLEURY, M. T. L. (Orgs.).

Internacionalização e os países emergentes. São Paulo: Atlas, 2007.

VAHLNE, J.E; JOHANSON, J. From internationalization to evolution: the Uppsala model at 40 years. Journal of International Business Studies, New York, n. 48, v. 9, dez. 2017. DOI: https://doi.org/10.1057/s41267-017-0107-7.

DE VILLA, M. A; RAJWANI, T.; LAWTON, T. Market entry modes in a multipolar world: Untangling the moderating effect of the political environment. International Business Review, v. 24, n. 3, p. 419-429, jun. 2015. DOI:

https://doi.org/10.1016/j.ibusrev.2014.10.001. 